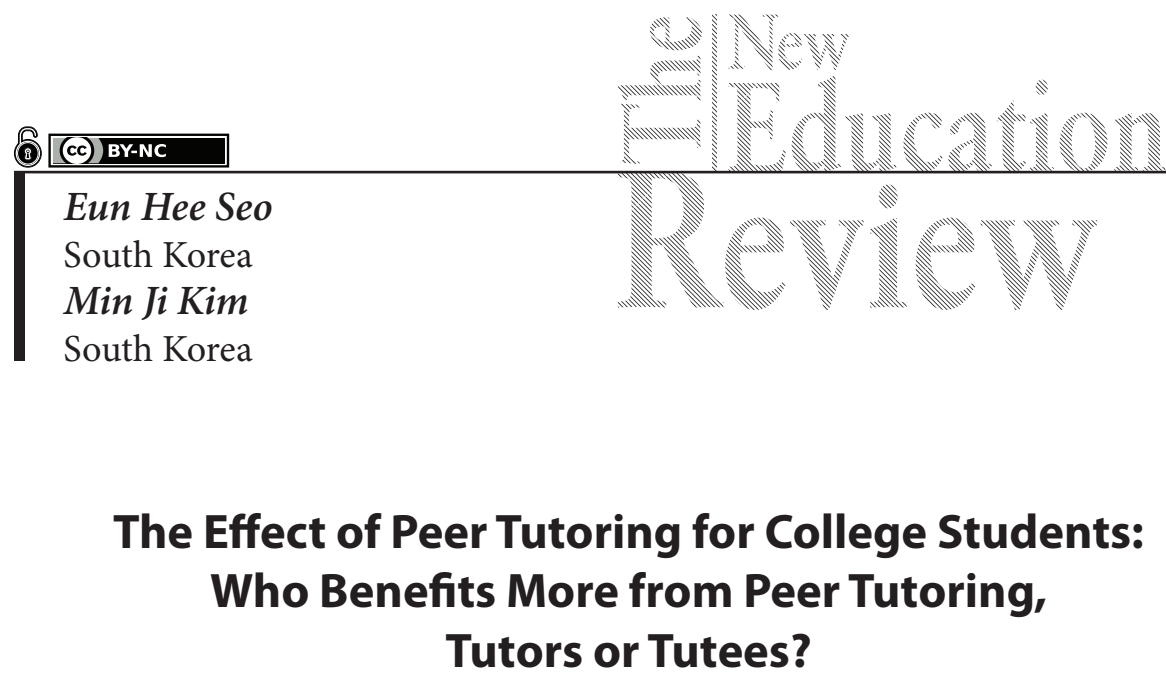

DOI: 10.15804/tner.2019.58.4.07

\begin{abstract}
The objective of this study was to examine the effect of peer tutoring on college students' academic achievement and, as well, their competencies in communication and collaboration. In particular, we investigated whether or not the effect of peer tutoring depends on the role taken in peer tutoring. 373 Korean college students attending peer tutoring participated in this study. A pre-post design employing a self-report questionnaire was used. The results indicated that peer tutoring improved both academic achievement and communicative and collaborative skills. The findings also suggested that the effect of peer-tutoring on academic achievement and responsibility for teamwork was valid only with regard to those in the role of tutees. The implications of this study are discussed.
\end{abstract}

Key words: peer tutoring, communication, collaboration, academic achievement, tutee, tutor

\title{
Introduction
}

Peer tutoring, a type of collaborative learning, aims at the acquisition of knowledge and skills through active support by peers (Falchikov, 2001). Previous studies have suggested that peer tutoring is an effective intervention to enhance academic gains (e.g., Zeneli, Thurston, \& Roseth, 2016); regulation skills (e.g., Backer, Keer, Moerkerke, \& Valcke, 2016); psychological adjustment (e.g., Fan- 
tuzzo, Riggio, Connelly, \& Dimeff, 1989); affective aspects of learning such as self-concept, self-esteem, and autonomy; and aspects of conduct (Miller, Topping, \& Thurston, 2010).

Despite growing consensus on the facilitative potential of peer tutoring (Backer et al., 2016), it is hard to find studies examining its influence on communication and collaboration. It is necessary to examine the effect of peer tutoring in these areas, given the process is based on interacting and communicating between tutors and tutees (Falchikov, 2001). In particular, the National Education Association has underscored the importance of these two competencies, along with critical thinking, problem solving, creativity, and innovation (World Economic Forum, 2015). Bowman-Perrott, Davis, Vannest, and Williams (2013) also suggested that, since most prior studies on peer tutoring have focused on academic gains thereby derived, it would be interesting to examine the benefit students receive from peer tutoring about behavior. Therefore, we aimed to probe the effect of peer tutoring not only on academic achievement, but also in skills relating to communication and collaboration; the population studied were college students.

Although many studies have investigated the efficacy of peer tutoring across a range of performance-related variables, most did not consider the role taken in peer tutoring. Unlike reciprocal peer tutoring which is characterized by exchange between the roles of tutor and tutee, in typical peer tutoring, the roles of tutors or tutees are fixed. Due to the nature of the tutoring, the role and responsibility of tutors are very different from those of tutees. Peer tutoring enables each tutor and tutee to experience the distinct benefits derived from providing and receiving academic guidance (e.g., Falchikov 2001). In order to understand the influence of peer tutoring in more detail, the effect of peer tutoring should be divided and analyzed depending on the role taken in peer tutoring. Therefore, the second purpose of the study is to investigate differences in the effects of peer tutoring on tutors vs tutees.

\section{Problem of the Research}

The objective of this study is to examine the effect of peer tutoring on academic achievement and the competencies of communication and collaboration of college students. Mainly, we verify whether or not the effect depends on the role taken in peer tutoring.

The hypotheses of this study were established as follows:

First, as a result of peer tutoring, there will be a significant improvement in college students' academic achievement and communicative and collaborative competencies. 
Second, there will be a significant difference between tutors and tutees in the effects of peer tutoring on college students' academic achievement and communicative and collaborative competencies.

\section{Methodology of Research}

\section{General Background of Research}

Many recent investigations have examined the effect of peer tutoring in various settings; most have found positive results. A large number of studies have found that peer tutoring contributes to an improvement in academic achievement and cognitive functioning in a range of areas (Zeneli et al., 2016; Backer et al., 2016). Moreover, peer tutoring frequently produces socioemotional gains: tutees have been found to be more cooperative and respectful toward peers and teachers while also exhibiting higher self-esteem (Gensemer, 2000). Also, cooperative groupings provide social advantages: students exercise and learn collaborative skills such as disagreeing constructively, expressing appreciation and encouragement, communicating with others, making cooperatively-derived decisions, and managing conflicts (Johnson \& Johnson, 1992). Students can also develop verbal communication skills, negotiation skills, and diplomacy (Topping, 1998).

Peer tutoring involves the utilization of academically successful tutors, advanced in their understanding of subject matter or academic skills, who provide learning assistance to less-advanced tutees. Peer tutoring studies have found positive, but differing, educational outcomes for tutors and tutees: while the former have reported an improvement in leadership and teaching skills as well as enhanced confidence, the latter have described increased satisfaction and enriched learning experience (Burgess, McGregor, \& Mellis, 2014). In particular, studies have explored the effects of tutees' academic achievement (Leung, 2015), communication (Nomura, Onishi, \& Kato, 2017), and collaboration (Kim \& Kim, 2017). Peer tutoring settings are assumed to have a beneficial impact on the tutor's academic and personal levels, in addition to their developing positive social skills (Colvin, 2007). Tutors have also been found to acquire helpful experience in facilitation and communication skills (Nestel \& Kidd, 2005).

\section{Research Sample}

Participants in the study were undergraduate students who attended a peer tutoring programme run by the center for teaching and learning (CTL) of a Korean university during the spring and fall semesters of 2018. Initially, 377 students 
registered for the programme. Of those, 373 students agreed to participate in the study; they comprised the sample of this research. Participants were well informed about the study in advance. Among the participants, there were 104 tutors and 269 tutees; there were 196 (52.5\%) men and 177 (47.5\%) women. The distribution across grade levels was: 47 (12.6\%) first-year students; 90 (24.1\%) sophomores; $114(30.6 \%)$ juniors; and $122(32.7 \%)$ seniors. The participants represented a wide range of academic majors.

\section{Instrument}

In order to assess the competencies of communication and collaboration, this study used the Core Competency Test for College Students (Kim et al., 2019). Among the five competencies assessed by the instrument, we used competencies of communication (11 items, $\alpha=.91$ on pretest and .93 on post-test) and collaboration (10 items, $\alpha=.91$ on pretest and .94 on post-test). The competency of communication consists of two dimensions: listening ability (five items, $\alpha=$ .83 on pretest and .88 on post-test, e.g., 'I listen carefully to what others say') and speaking ability (six items, $\alpha=.88$ on pretest and .91 on post-test, e.g., 'I am able to express my opinion clearly and logically'). The competency of collaboration was composed of two dimensions: Responsibility for teamwork (five items, $\alpha=.89$ on pretest and .93 on post-test, e.g., 'I participate in teamwork in good faith') and mutual respect (five items, $\alpha=.85$ on pretest and .88 on post-test, e.g., 'I respect other's perspectives or opinions while working together'). A five-point Likert-type scale $(1=$ not at all true, $5=$ very true $)$ was used as the response format for all items.

For students' academic achievement, data on the Grade Point Average (GPA) in the spring and fall semesters of 2018 were obtained with the consent of participants. The range of GPA was from 0.94 to 4.5 in the spring semester and from 1.00 to 4.5 in the fall semester of 2018.

\section{Intervention}

The CTL recruited applicants for peer tutoring at the beginning of the semester. The academic qualification for serving as a tutor is an $\mathrm{A}$ in the course which he/ she will teach (the logic being that, if the tutor's academic ability is insufficient to understand the contents to be taught, the tutoring programme can be challenging; Robinson et al., 2005). Some tutors voluntarily paired up with tutees. Other tutors were matched with tutees by the CTL. Tutors were primarily responsible for the tutee's learning in a particular course. Content areas for study were not limited, since peer tutoring is an effective intervention regardless of the content area 
(Bowman-Perrott et al., 2013). An orientation on peer tutoring was provided to the students to elaborate on the rules and requirements of peer tutoring (as peer tutoring has been found to ineffective if the tutor has a poor understanding of his/her role or does not perform it properly; Robinson et al., 2005). Participants were informed about their responsibilities as tutors and tutees and given examples of good practices of peer tutoring. Primarily, tutors were taught general teaching skills, including interacting with tutees, providing appropriate scaffolds, giving constructive feedback, and so on. Participants were expected to conduct more than eight successive face-to-face peer tutoring sessions. Tutors uploaded more than eight self-written journals recounting the activities they did in the learning management system (LMS) every two weeks. After the end of the term, tutors who had met the requirement of the peer tutoring won a scholarship, based on the research that peer tutoring interventions that used rewards had a larger effect size than those that did not (Bowman-Perrott et al., 2013).

\section{Procedures}

The study is based on a one group time-series, quasi-experimental design. The intervention period was 15 weeks, with the participants following a prescribed peer tutoring process. The self-reported questionnaire was implemented to assess participants' competencies of communication and collaboration through the LMS at the beginning and the end of the semester.

\section{Data Analysis}

The pre- and post-questionnaire data regarding students' self-reported competencies of communication and collaboration and GPA in the spring and fall semester of 2018 were analyzed quantitatively. First, Cronbach's $\alpha$ and descriptive statistics were computed. Paired t-tests were used to examine changes in academic achievement and communicative and collaborative competencies after the peer tutoring. Pretest and post-test scores of variables were compared through a paired t-test. An ANOVA (analysis of covariance) was conducted to verify the difference in the effect of peer tutoring between tutors and tutees.

\section{Results of the Research}

First, the descriptive information of each variable measured in the study was presented (see Table 1). The data show that students report relatively high levels of collaboration, both in the pre-test $(M=4.30, S D=.47)$ and post-test $(M=4.45, S D$ 
$=.53$ ), as compared to other variables. All the means of variables in the post-test were higher than those of variables in the pre-test.

Table 1. Descriptive statistics for variables

\begin{tabular}{lcccccc}
\hline \multirow{1}{*}{ Variables } & \multicolumn{2}{c}{ Tutee } & \multicolumn{2}{c}{ Tutor } & \multicolumn{2}{c}{ Total } \\
\cline { 2 - 7 } & $\begin{array}{c}\text { Pre } \\
\boldsymbol{M}(\boldsymbol{S D})\end{array}$ & $\begin{array}{c}\text { Post } \\
\boldsymbol{M}(\boldsymbol{S D})\end{array}$ & $\begin{array}{c}\text { Pre } \\
\boldsymbol{M}(\boldsymbol{S D})\end{array}$ & $\begin{array}{c}\text { Post } \\
\boldsymbol{M}(\boldsymbol{S D})\end{array}$ & $\begin{array}{c}\text { Pre } \\
\boldsymbol{M}(\boldsymbol{S D})\end{array}$ & $\begin{array}{c}\text { Post } \\
(\boldsymbol{S D})\end{array}$ \\
\hline $\begin{array}{l}\text { Academic } \\
\text { achievement }\end{array}$ & $3.39(.66)$ & $3.55(.62)$ & $3.83(.45)$ & $3.86(.50)$ & $3.52(.64)$ & $3.64(.60)$ \\
\hline Communication skills & $3.93(.55)$ & $4.23(.58)$ & $4.05(.53)$ & $4.25(.57)$ & $3.97(.54)$ & $4.24(.57)$ \\
\hline Listening skills & $4.14(.56)$ & $4.37(.59)$ & $4.20(.52)$ & $4.36(.57)$ & $4.16(.55)$ & $4.37(.58)$ \\
\hline Speaking skill & $3.72(.65)$ & $4.10(.67)$ & $3.90(.60)$ & $4.14(.63)$ & $3.78(.64)$ & $4.11(.66)$ \\
\hline Collaboration & $4.26(.47)$ & $4.42(.58)$ & $4.38(.48)$ & $4.53(.41)$ & $4.30(.47)$ & $4.45(.53)$ \\
\hline Mutual respect & $4.18(.52)$ & $4.37(.62)$ & $4.25(.58)$ & $4.45(.48)$ & $4.20(.54)$ & $4.40(.57)$ \\
\hline $\begin{array}{l}\text { Responsibility for } \\
\text { teamwork }\end{array}$ & $4.33(.53)$ & $4.45(.63)$ & $4.52(.49)$ & $4.61(.43)$ & $4.40(.52)$ & $4.51(.57)$ \\
\hline
\end{tabular}

\section{The Effect of Peer Tutoring}

In order to examine the effect of peer tutoring, a paired t-test was employed. For all participants, difference in the GPA was found to be statistically significant $(t=-4.41, p<.001)$. The results also showed that collaborative competency in the post-test was significantly higher than in the pre-test $(t=-3.72, p<.001)$. There were positive pretest-to-post-test changes in both mutual respect $(t=-2.50$, $p<.05)$, and responsibility for teamwork $(t=-4.24, p<.001)$. The gap in communication skills was also statistically significant $(t=-6.30, p<.001)$. The trend for speaking skills $(t=-6.95, p<.001)$ was particularly notable; it was larger compared to other variables, including listening skills $(t=-4.34, p<.001)$.

\section{The Difference in the Effect of Peer Tutoring between Tutors and Tutees}

In order to examine the effect of peer tutoring on tutors and tutees, a paired t-test was employed. The results showed that, for tutees, the change in GPA was statistically significant $(t=-4.65, p<.001)$. Improvement in communication skills was also statistically significant $(t=-5.46, p<.001)$. A pretest-to-post-test change was significantly positive in both speaking skills $(t=-6.48, p<.001)$ and listening skills $(t=-3.50, p<.01)$. The gap in collaboration was also statistically significant $(t$ $=-2.96, p<.01)$. There were significant pretest-to-post-test changes in both mutual respect $(t=-2.10, p<.05)$ and responsibility for teamwork $(t=-3.39, p<.01)$. 
In the case of tutors, the change in GPA was not statistically significant ( $t=$ $-.69, p>.05)$. The gap in communication skills between pre- and post-tests were statistically significant $(t=-3.15, p<.01)$. Both speaking skill $(t=-2.92, p<.01)$ and listening skill $(t=-2.68, p<.05)$ became better than before. The gap in collaboration was also statistically significant $(t=-2.27, p<.05)$. On the other hand, while there were no significant pretest-to-post-test changes in responsibility for teamwork $(t=-1.35, p>.05)$, the gap of mutual respect was statistically significant $(t=-2.53, p<.05)$.

In order to examine the difference of the effect of peer tutoring between tutors and tutees, an ANCOVA using the pre-test score as a covariate was employed. The finding showed that there was no statistically significant difference in improvement of academic achievement and competencies of communication and collaboration between tutors and tutees (academic achievement $F=.78, p>.05$; communication $F=.28, p>.05$; listening skill $F=.09, p>.05$; speaking skill $F=.45, p>.05$; collaboration $F=.52, p>.05$; mutual respect $F=.33, p>.05$; responsibility for teamwork $F=.81, p>.05)$.

\section{Discussion}

The effect of peer tutoring on academic achievement and competencies of communication and collaboration for college students was analyzed in this study. Mainly, we explore whether or not the effect of tutoring depends on the role taken in peer tutoring.

Two significant findings emerged from this study. First, peer tutoring might have a positive influence on a student's academic achievement and communicative and collaborative competencies. The result indicated an apparent pretest-to-post-test improvement in these domains. This finding is consistent with prior studies documenting the effectiveness of peer tutoring in enhancing academic achievement (e.g., Zeneli et al., 2016); communication skills (e.g., Nestel \& Kidd, 2005); and collaboration (e.g., Gensemer, 2000; Johnson \& Johnson, 1992). Tutors and tutees explicitly felt the need to regulate their learning processes and their interactions with other students; they engaged in collaborative goal setting, checked cooperatively on learning strategies and outcomes, and controlled their own and each other's comprehension (Volet, Summers, \& Thurman, 2009). This implies that peer tutoring might be a promising facilitator for higher communication and collaboration.

The interesting thing was that the overall grade point average of tutees, not the grade of the specific course connected to the peer tutoring, was improved. This 
might be due to the fact that tutees not only learn what they learn but also how they learn during peer tutoring (Topping, 2005). Previous studies have suggested that, in such engagements, students share knowledge construction and practice metacognitive regulation - which is closely related to academic achievement through peer tutoring (Backer et al., 2016). It might, therefore, enhance their overall scores.

Second, while the positive influence of peer tutoring on communication competency was significant for both tutors and tutees, the effects of peer tutoring on academic achievement and collaborative competency of tutors might be distinct from those of tutees. Although the difference between tutors and tutees was not statistically significant, the effect of peer tutoring on academic achievement and responsibility for teamwork was valid only for tutees. This result supports prior studies (e.g., Burgess et al., 2014), which found that peer tutoring works differentially, depending on the participant's role. Though previous studies (e.g., Fantuzzo et al., 1989) found academic benefits associated with peer tutoring for both tutees and tutors, this study showed that, while academic achievement of tutees improved, this positive change could not be discerned in tutors. These findings can be interpreted as deriving from the fact that tutors are expected to take interest in the progress of their tutees, not their own. Therefore, peer tutoring might not contribute to the tutor's academic improvement; still this does not mean that tutors do poorly in their university course.

Regarding collaboration, contrary to expectations, responsibility for the teamwork on the part of tutors did not improve significantly, either. Although the post-responsibility for teamwork was improved compared to the prior condition, this was not statistically significant. This might be due to the fact that the existing level of responsibility for teamwork was quite high (4.52 out of 5); thus, it would have been challenging to improve it even more. It also suggests that students with high levels of cooperation may prefer the tutoring programme and tend to apply for it. Peer tutors' enhanced competence can occur rather naturally (Falchikov, 2001). Gaustad (1993) insisted that the tutoring programme can be challenging if the communication and cooperation of the tutor are not excellent. Van Berkel and Dolmans (2006) emphasized that the cooperative learning facilitation ability of tutors had a positive effect on the interaction of tutoring groups. In sum, although peer tutoring is effective in academic and affective aspects overall, different change patterns between tutors and tutees were observed in the domains of academic achievement and collaboration. While the pre- to post-test change for tutees was significantly positive in all dependent variables, that of tutors was only partially 
positive. It was thus confirmed that tutees appear to derive more benefit from peer tutoring than do the tutors.

Despite interesting findings that add to the research on peer tutoring, the study has some limitations. First, the results need to be interpreted with caution, since the participant group might not be representative either of college students worldwide, or those in different peer tutoring settings. The lack of control group also remains a methodological challenge in the study. Further research is needed to examine the influence of peer tutoring in a rigorously controlled setting. A final limitation is that this study used a self-reported questionnaire to measure the competencies of communication and collaboration. It would be worthwhile to examine the effect of peer tutoring through objective observation of these two competencies.

\section{Conclusion}

Significant pre-post gains were noted in academic achievement and communicative and collaborative competencies through peer tutoring. Peer tutoring might be an especially effective intervention for tutees, rather than tutors. The study helps educators understand the characteristics of tutors and, further, appreciate that peer tutoring should be designed to support the unique needs of tutors as well as tutees.

\section{Acknowledgments}

This work was supported by the Gachon University research fund of 2019 (GCU-20190370).

\section{References}

Backer, L.D., Keer, H.V., Moerkerke, B., \& Valcke, M. (2016). Examining evolutions in the adoption of metacognitive regulation in reciprocal peer tutoring groups. Metacognition Learning, 11 (2), 187-213.

Bowman-Perrott, L., Davis, H., Vannest, K., \& Williams, L. (2013). Academic benefits of peer tutoring: A meta-analytic review of single-case research. School Psychology Review, 42 (1), 39-55.

Burgess, A., McGregor, D., \& Mellis, C. (2014). Medical students as peer tutors: a systematic review. BMC Medical Education, 14 (1), 115-122.

Colvin, J.N. (2007). Peer tutoring and social dynamics in higher education. Mentoring and Tutoring, 15 (2), 165-181. 
Falchikov, N. (2001). Learning together. Peer tutoring in higher education. London: Routledge Falmer.

Fantuzzo, J.W., Dimeff, L.A., \& Fox, S.L. (1989). Reciprocal peer tutoring: A multimodal assessment of effectiveness with college students. Teaching of Psychology, 16 (3), 133-135.

Gaustad, J. (1993). Peer and cross-age tutoring. ERIC Digest, 79.

Gensemer, P. (2000). Effectiveness of cross-aged and peer mentoring programs. Educational Researcher, 24(2). 1-14.

Johnson, D.W., \& Johnson, R. (1992). Positive interdependence: Key to effective cooperation. In R. Hertz-Lazarowitz \& N. Miller (Eds.), Interaction in cooperative groups: The theoretical anatomy of group learning (pp. 174-200). New York: Cambridge University Press.

Kim, O., \& Kim, H. (2017). Identifying predicting variables of the tutees learning flow in tutoring program. Korean Journal of General Education 11 (2), 563-584.

Kim, E., Kang, S., Kim, J., No, W., Seo, E., Song, S., Won, Y., \& Lim, H. (2019). Core competency test for college student questionnaire manual. Seoul: Inset.

Miller, D., Topping, K., \& Thurston, A. (2010). Peer tutoring in reading: The effects of role and organization on two dimensions of self-esteem. British Journal of Educational Psychology, 80 (3), 417-433.

Nestel, D., \& Kidd, J. (2005). Peer assisted learning in patient-center interviewing: The impact on student tutors. Medical teacher, 27 (5), 439-444.

Nomura, O., Onishi, H., \& Kato, H. (2017). Medical students can teach communication skills-A mixed methods study of cross-year peer tutoring. BMC Medical Education, 17 (1), 103.

Robinson, D.R., Schofield, J.W., \& Steers-Wentzell, K.L. (2005). Peer and cross-age tutoring in math: Outcomes and their design implications. Educational Psychology Review, 17 (4), 327-362.

Topping, K.J. (1998). Peer assessment between students in colleges and universities. Review of Educational Research, 68 (3), 249-276.

Topping, K.J. (2005). Trends in peer learning. Educational Psychology, 25 (6), 631-645.

Van Berkel, H.J., \& Dolmans, D.H. (2006). The influence of tutoring competencies on problems, group functioning and student achievement in problem-based learning. Medical Education, 40 (8), 730-736.

Volet, S., Summers, M., \& Thurman, J. (2009). High-level co-regulation in collaborative learning: How does it emerge and how is it sustained?. Learning and Instruction, 19 (2), 128-143.

World Economic Forum. (2015). New vision for education: Unlocking the potential of technology. British Columbia Teachers' Federation.

Zeneli, M., Thurston, A., \& Roseth, C. (2016). The influence of experimental design on the magnitude of the effect size-peer tutoring for elementary, middle and high school settings: A meta-analysis. International Journal of Educational Research, 76, 211-223. 